\title{
Anaesthetic management of acute airway obstruction
}

\author{
Patrick Wong ${ }^{1}$, MBBS, FRCA, Jolin Wong ${ }^{1}$, MBBS, MMed, May Un Sam Mok ${ }^{1}$, MBChB, FRCA
}

\begin{abstract}
The acutely obstructed airway is a medical emergency that can potentially result in serious morbidity and mortality. Apart from the latest advancements in anaesthetic techniques, equipment and drugs, publications relevant to our topic, including the United Kingdom's 4th National Audit Project on major airway complications in 2011 and the updated American Society of Anesthesiologists' difficult airway algorithm of 2013, have recently been published. The former contained many reports of adverse events associated with the management of acute airway obstruction. By analysing the data and concepts from these two publications, this review article provides an update on management techniques for the acutely obstructed airway. We discuss the principles and factors relevant to the decision-making process in formulating a logical management plan.
\end{abstract}

Keywords: airway obstruction, goitre, intratracheal, intubation

\section{INTRODUCTION}

Management of acute airway obstruction (AAO) in the adult surgical patient was a matter of concern highlighted in the 1998 United Kingdom (UK) National Confidential Enquiry into Perioperative Deaths and a subsequent journal editorial by Mason et al. ${ }^{(1,2)}$ In 2011, the 4th National Audit Project (NAP4) in the UK, which was investigating anaesthesia-related major airway complications, included 50 obstructed airway cases. ${ }^{(3)}$ Many of these patients were not ideally managed and some required an emergency surgical airway procedure and/or suffered serious sequelae, including brain damage and death. The American Society of Anesthesiologists' (ASA) difficult airway algorithm, updated in 2013, ${ }^{(4)}$ is also discussed. This article analyses and contributes to the data and concepts from NAP4 and the ASA algorithm, showing how the basic template from Mason et $\mathrm{al}^{(2)}$ is still pertinent two decades on.

\section{METHODS}

The article focuses on causes of AAO in the adult surgical patient relating to an underlying pathology. Major airway complications occur for many reasons, including poor airway assessment, failure to create a strategy and failure to plan for failure. ${ }^{(3)}$ Some of these reasons are considered preventable.

The Difficult Airway Society's algorithm for unanticipated difficult airway specifically excludes patients with AAO of the upper airway. ${ }^{(5)}$ This is partly due to the fact that most cases of $\mathrm{AAO}$ are anticipated and require complex airway management strategies. The ASA's difficult airway algorithm provides guidelines for both anticipated and unanticipated cases, but lacks specific guidelines on the management of AAO. ${ }^{(4)}$ Therefore, this article analysed the generic basic management choices of these guidelines, and extrapolated the choices and reasoning to be applied to AAO use. Logical Plans A, B and C were, in turn, formulated based on Mason et al's $\mathrm{s}^{(2)}$ algorithm for AAO. A review of the literature found that it supported the principles and applicability of both these algorithms. Deviations from them may lead to serious morbidity and mortality, as highlighted in the recent NAP4 report. $^{(3)}$ Recognition and management of AAO requires a multidisciplinary approach, as there are many surgical causes of AAO, and may involve emergency department personnel, and ear, nose and throat (ENT), and thoracic surgeons. Usually, input from the anaesthesiologist is required to provide general anaesthesia for surgery or as part of the resuscitation team in cases of imminent complete AAO. On occasion, an emergency surgical airway procedure performed under local anaesthesia by the ENT surgeon is warranted.

In airway management, it is vitally important to have a Plan A, B and C, i.e. two backup plans if the initial Plan A fails. We routinely use the template proposed by Mason et al, ${ }^{(2)}$ as it satisfies and incorporates two sets of preconditions essential for safe management of AAO: firstly, establishing the cause, location and degree of the obstruction; and secondly, determining which elements of the four ASA basic management choices are most appropriate to secure the airway. ${ }^{(4)}$ It is vital to understand how each of these choices will affect the presenting AAO case, possibly in a deleterious way.

We take the opportunity to update the recommendations proposed by Mason et $\mathrm{al}^{(2)}$ in 1999 . Firstly, we place less emphasis on gas induction following reports of morbidity using that technique, ${ }^{(3)}$ although we acknowledge that it is still an important option in AAO management. Secondly, there is a recent recognition that the use of muscle relaxants may be beneficial in certain cases of difficult airway and airway obstruction. ${ }^{(6,7)}$ This is further supported by the introduction of sugammadex in 2008. ${ }^{(8)}$ Thirdly, we discuss the recent use of videolaryngoscopes. Lastly, we discuss in greater detail the place of extracorporeal oxygenation in the management of AAO.

\section{CAUSES, LOCATION AND DEGREE OF OBSTRUCTION}

There are many surgical causes of AAO in the literature. Infective causes include Ludwig's angina, ${ }^{(9)}$ tonsillar or pharyngeal 
wall abscess, ${ }^{(10)}$ and acute epiglottitis. ${ }^{(11)}$ Inflammatory causes include subglottic/tracheal stenosis, ${ }^{(7)}$ goitre $^{(12)}$ and lingual tonsillar hypertrophy. ${ }^{(13)}$ Neoplastic causes include laryngeal or tracheobronchial cancers, ${ }^{(14)}$ and those associated with mediastinal mass syndrome. ${ }^{(15)} 80 \%$ of emergency awake tracheostomies are related to malignant disease. ${ }^{(16)}$ Laryngospasm, which occurs in less than $1 \%$ of patients undergoing general anaesthesia, ${ }^{(17)}$ is not included in this article, as it is usually an unanticipated phenomenon due to an exaggerated protective airway reflex.

Most cases of AAO are anticipated from symptoms, signs and results of medical investigations. Symptoms include shortness of breath, hoarseness of voice, noisy breathing and postural symptoms. The latter include sleeping on multiple pillows, preferring to lie on one side or waking up at night feeling breathless. Severity of symptoms is also affected by the speed of onset. Signs indicating difficult intubation may be due to the underlying disease process. Stridor or 'hot potato voice', which indicates supraglottic involvement or tumour, is traditionally associated with a reduction of the tracheal diameter of more than $50 \%$. Bedside tests may indicate difficult face mask ventilation or intubation. Independent predictors for difficult face mask ventilation are: obesity, aged 55 years and above, history of snoring, lack of teeth, the presence of a beard, Mallampati Class III or IV, and abnormal mandibular protrusion test. ${ }^{(18)}$ Predictors for difficult intubation include: decreased interdental and thyromental distances, increased Mallampati scores, and decreased neck movement. ${ }^{(19,20)}$ One study demonstrated 12 independent predictors of combined difficult face mask ventilation and laryngoscopy: aged 46 years and above; body mass index $\geq 30$; male gender; Mallampati Class III or IV; neck mass or radiation changes; limited thyromental distance; sleep apnoea; limited cervical spine mobility; limited jaw protrusion; thick neck; presence of teeth; and beard. ${ }^{(21)}$ Patients with lingual tonsillar hypertrophy may not present with symptoms and signs, as their tonsillar tissue is slow-growing and hidden behind the base of the tongue. These patients may, therefore, present as unanticipated cases of difficult airway, which may lead to serious morbidity and even death. ${ }^{(13,22)}$

Diagnostic information is important to determine the location and degree of AAO, and whether it is an annular and/or fixed, or a large pedunculated or 'ball valve' type. The latter requires the patient to maintain spontaneous ventilation (SV). These can all be investigated by flexible nasendoscopy and radiological imaging. Flexible nasendoscopy is a noninvasive test and does not require airway topicalisation, thereby avoiding airway irritation that can potentially cause laryngospasm and loss of the airway. ${ }^{(23-28)}$ It provides a bird's eye view of the supraglottis and allows diagnostic information to be obtained, including the accessibility of the lesion and degree of obstruction. NAP4 reported that flexible nasendoscopy was "not used to evaluate the airway as often as it was indicated" ${ }^{(3)}$ Radiography, computed tomography and magnetic resonance imaging of the airway are helpful, but may not be practical or appropriate in the presence of severe AAO.
The location of the lesion is important as it determines if the anaesthesiologist can access and bypass it with a given airway device or technique. The various locations can be broadly divided into oropharyngeal, laryngeal and supraglottic structures, and upper and lower tracheal regions. Obstructive lesions in the oropharynx may be bypassed from above with nasal fibreoptic intubation or from below with cricothyroidotomy or surgical tracheostomy. Large obstructive lesions in the larynx and trachea may prohibit the use of certain airway techniques. Awake fibreoptic intubation (AFOI) may cause a 'cork in a bottle' obstruction or laryngospasm in cases of severe AAO. ${ }^{(23-28)} \mathrm{A}$ tracheostomy may not be able to access and bypass large or lowlying lesions (e.g. retrosternal goitres or tracheobronchial lesions).

A relatively common upper tracheal lesion is the goitre. These are usually chronic lesions but, in rare circumstances $(<1 \%)_{\text {, }}^{(29)}$ they can present as $\mathrm{AAO}$ with considerable management difficulties for the anaesthesiologist, and ENT and thoracic surgeons. ${ }^{(12,30)} \mathrm{A}$ goitre can cause a mass effect on surrounding structures, resulting in Pemberton's sign when the gland acts as a 'thyroid cork' at the thoracic inlet and AAO. ${ }^{(31)}$ If large, it can present clinicians with various challenges. Firstly, laryngoscopy may be difficult. ${ }^{(32)}$ Secondly, the trachea may be compressed and deviated. Thirdly, the goitre may be an obstacle to a surgical airway procedure. Lastly, the goitre may cause a mediastinal mass syndrome. If a surgical airway procedure is needed in patients with large goitre presenting with $\mathrm{AAO}$, the procedure may be difficult or impossible, although there have been successful cases. ${ }^{(33,34)}$ In cases where a surgical airway procedure would be unable to bypass the obstruction, preinduction cardiopulmonary bypass may be required.

\section{BASIC MANAGEMENT CHOICES}

The 2013 ASA algorithm requires the anaesthesiologist to consider the relative merits and feasibility of the four basic management choices, i.e. airway devices and techniques used to secure the airway. ${ }^{(4)}$ These are: (a) awake or asleep intubation; (b) SV or ablation of SV (e.g. applying positive pressure ventilation to paralysed patients); (c) non-invasive or invasive airway devices; and (d) direct or indirect laryngoscopy to facilitate tracheal intubation. ${ }^{(4)}$ The decision-making process in formulating logical (and safe) Plans A, B and C are presented later in this article.

\section{Awake or asleep intubation}

The decision to keep a patient awake or asleep is derived from predictions of the ability to maintain oxygenation/ventilation and secure the airway. Difficult face mask ventilation requires the use of an oral airway or two hands; ${ }^{(35)}$ the incidence of difficult and impossible face mask ventilation is $1.4 \%$ and $0.15 \%$, respectively. ${ }^{(36)}$ Difficult intubation is commonly defined as a Cormack-Lehane view of Grade 3 or 4 on direct laryngoscopy, (37) and difficult and failed intubation are similarly rare $(5.8 \%$ and $0.1 \%$, respectively). ${ }^{(20,38)}$ Bedside airway assessments used to predict these difficulties have low to moderate predictive power. ${ }^{(20)}$ In general, the majority of patients are easy to ventilate and intubate, and most patients with a normal appearance can be intubated after induction of anaesthesia (asleep intubation). 
Anaesthesia causes airway obstruction due to a loss of muscle tone, suppression of protective arousal responses ${ }^{(39)}$ and decrease in respiratory reserve (due to atelectasis, right-to-left shunt, decrease in functional respiratory capacity, alveolar collapse and airway closure). ${ }^{(40-42)}$ Therefore, as the 'margin of safety' is narrowed, full pre-oxygenation with the 'three-minute tidal volume' or 'eight deep breath' technique and transnasal oxygen insufflation is beneficial, as it prolongs safe apnoea time. ${ }^{(43,44)}$ Even if a difficult airway is encountered, $90 \%$ of patients with CormackLehane Grade 3 views (more common than Grade 4 views) can be successfully intubated with the aid of standard airway adjuncts such as the bougie and/or McCoy laryngoscope. ${ }^{(45)}$ However, the incidence of difficult airway in ENT is higher in surgical patients than the general population $(3.5 \%-15.7 \%$ and $2.5 \%$, respectively). ${ }^{(46)}$ This is especially so if the surgery is for cancer.

If face mask ventilation or intubation is predicted to be difficult, and attempts are at high risk of morbidity, the airway should be secured before induction of anaesthesia (awake intubation). This maximises the 'margin of safety', as airway muscle tone and reflexes are maintained, ${ }^{(47)}$ and respiratory function is unaffected by anaesthetic agents. It also avoids the risk of a post-induction 'cannot intubate, cannot ventilate' (CICV) scenario, which has an incidence of $0.01 \%-0.17 \%$. $^{(3,48)}$ The two most common techniques are AFOI and awake tracheostomy, although they are not without risks. ${ }^{(3)}$ Rarely are other techniques used in awake patients with $\mathrm{AAO}$, such as direct or indirect laryngoscopy, ${ }^{(49,50)}$ rigid bronchoscopy ${ }^{(51)}$ and femoral vessel cannulation for cardiopulmonary bypass. ${ }^{(15,52)}$

\section{Preserved or ablated spontaneous ventilation}

SV is preserved in the awake state or during anaesthesia after careful titration of intravenous or volatile agents. The latter, in theory, allows a 'bailout' exit strategy in the event of failure to secure the airway or total airway obstruction, by allowing the patient to wake up with cessation of delivery of the volatile agent. Gas induction with sevoflurane is performed in a slow, stepwise manner or by starting at a high $8 \%$ concentration. However, it should be noted that the minimum alveolar concentration of sevoflurane for endotracheal intubation is much higher than for surgical incision $\left(4.5 \%\right.$ vs. $1.7 \%-2.1 \%$, respectively). ${ }^{(53-55)}$

Under acceptable intubating conditions, induction takes approximately six minutes using $7 \%$ sevoflurane in normal patients ${ }^{(56)}$ but much longer in patients with AAO, as the obstruction prevents delivery of the volatile agent. Furthermore, induction and intubation with $8 \%$ sevoflurane without the use of muscle relaxants is associated with a higher failed intubation rate $^{(57)}$ and up to $10 \%-25 \%$ of upper airway complications, such as breath-holding and coughing. ${ }^{(58,59)}$ In patients with AAO, laryngospasm is more common. ${ }^{(17)}$ NAP4 also reported several cases of failed gas induction leading to serious morbidity, including airway obstruction, laryngospasm, failed intubation necessitating surgical airway procedure, and cardiac arrest. ${ }^{(3)}$ It cautioned that gas induction may fail with loss of airway and failure to wake up, and recommended a clear and ready rescue plan.
Waking a patient up, and ensuring that he can maintain adequate airway and respiratory function thereafter, is not always possible for several reasons. The patient may have poor respiratory reserve due to pre-existing comorbidities and an inability to comply with full pre-oxygenation, both of which quicken the onset of critical haemoglobin desaturation. ${ }^{(60)}$ The return of airway muscle tone and SV is also suppressed by residual anaesthetic drugs. In simulations of complete airway obstruction following gas induction, there are conflicting results as to which volatile agent offers the fastest wake-up time. One study showed that sevoflurane (with its lower solubility and slower redistribution) was found to decline three times slower than halothane, resulting in slower wake-up time. ${ }^{(61)}$ Another study showed faster wake-up time with sevoflurane. ${ }^{(62)}$ If SV is ablated by a sufficiently large dose of intravenous anaesthetic agent and/or the use of muscle relaxants, the ability to wake the patient may also be lost.

The main advantages to using muscle relaxants are that they may improve face mask ventilation and intubating conditions. ${ }^{(63-66)}$ Further points for consideration are:

(a) Patients with fixed, annular laryngotracheal stenosis. One study showed that muscle paralysis improved ventilatory dynamics compared with SV. ${ }^{(7)}$ This should be distinguished from cases of large, pedunculated airway lesions, where muscle paralysis and positive pressure ventilation must be avoided, as they may cause a 'ball-valve' type obstruction.

(b) Choice of muscle relaxant. Traditionally, suxamethonium was used for patients with difficult airway due to its fast onset and offset of action. If failed intubation occurred, the patient would regain airway muscle tone and resume SV. However, Benumof et al reviewed clinical mean duration times of suxamethonium and related it to calculated apnoeic times following sudden complete airway obstruction. ${ }^{(60)}$ Calculations were based on a model of a healthy $70 \mathrm{~kg}$ adult under anaesthesia, after full preoxygenation. Times to reach critical haemoglobin desaturation $\left(\mathrm{SaO}_{2}<80 \%\right)$ and functional recovery of suxamethonium (mean time for single twitch height to recover to $50 \%$ ) were similar, i.e. 8.7 minutes and 8.5 minutes, respectively. However, in patients with $\mathrm{AAO}$ who are older and often have comorbidities, critical desaturation would occur much earlier, exposing the patient to unacceptable levels of hypoxia. One study even showed a mean duration time of 13.3 minutes for suxamethonium. ${ }^{(67)}$ Historically, longer-acting muscle relaxants are not used due to the inability to immediately reverse deep block if bailout is required. A new strategy is to use a rapid-sequence dose of the intermediate-acting rocuronium $(1.2 \mathrm{mg} / \mathrm{kg})$ and follow this with its reversal agent, sugammadex (16 mg/kg), if bailout is required. This combination gives a similar onset but faster offset time compared with suxamethonium. ${ }^{(68,69)}$ Sugammadex has been used to 'rescue' intense neuromuscular block after induction of patients with $\mathrm{AAO} ;{ }^{(70,71)}$ however, these cases were criticised for an overreliance on the drug's ability to guarantee rapid reversal, and a lack of logical induction, intubation and exit strategies. ${ }^{(72-79)}$ Other considerations include the cost and the time to find and draw-up sugammadex ${ }^{(80)}$ and the potential of developing negative pressure pulmonary oedema if the AAO 
remains unresolved but breathing resumes, generating a large, negative intrathoracic pressure.

(c) NAP4 recommends the use of muscle relaxants in CICV cases as they may resolve failure to ventilate caused by laryngospasm and aid mask ventilation. ${ }^{(3)}$

In symptomatic patients with large mediastinal masses or tracheobronchial lesions, maintaining SV and avoiding the use of muscle relaxants is considered the safest option. The resulting negative intrathoracic pressure helps to keep the intrathoracic airways open. ${ }^{(15,52)}$ Tracheal intubation can be achieved either by awake (e.g. AFOI) ${ }^{(81,82)}$ or asleep intubation, gas induction or carefully titrated target-controlled propofol infusion.

\section{Noninvasive or invasive airway devices}

In the UK, most patients undergoing general anaesthesia have their airways managed with noninvasive devices, such as a laryngeal mask airway (56\%) or tracheal tube (38\%). (3) Supraglottic airway devices have been used successfully for fixed annular obstructive lesions such as subglottic and tracheal stenosis. ${ }^{(7,83,84)}$ However, in head and neck surgery, due to the shared airway, a tracheal tube is usually indicated.

In upper airway obstruction, if flexible nasendoscopy and radiological imaging show that the tracheal tube cannot access and bypass the lesion, another airway device or technique is indicated. In AAO involving the larynx, this usually indicates a procedure involving the insertion of an invasive airway that will bypass the obstruction from below, such as cricothyroidotomy or tracheostomy. Both procedures can be performed electively (prophylactically) in the anticipated difficult airway, or in the emergency setting. NAP4 contained 58 attempted emergency surgical airway procedures: 9 (16\%) failed and 4 (7\%) patients died. ${ }^{(3)}$ Cricothyroidotomy can be classified into small bore ( $\geq 2 \mathrm{~mm}$ ), large bore ( $\geq 4 \mathrm{~mm}$ ) or surgical ( $\geq 6 \mathrm{~mm}) .{ }^{(85)}$ Small-bore cricothyroidotomy requires a high-pressure oxygen source like a jet ventilator using low or high frequency. In order to prevent barotrauma, the presence of a leak path (patent expiratory pathway) is essential. Large-bore and surgical cricothyroidotomy allow ventilation through the device itself, hence only require a low-pressure oxygen source. Leaks must not be present when these devices are used, so the cuff component of the device should be inflated in cases where the lesion has not caused total obstruction.

Despite the risk of barotrauma, subglottic high-frequency jet ventilation via small-bore cricothyroidotomy has been used electively for patients with severe airway compromise (6\% of patients had impossible face mask ventilation). ${ }^{(86)}$ RossAnderson et $\mathrm{al}^{(86)}$ achieved adequate ventilation in $95 \%$ of their patients using this technique, with minor complications occurring in $20 \%$. They used an automated jet ventilator with a pause pressure function, a pre-set airway pressure limit above which the alarms are set off and the ventilator stops jetting, thus minimising the risk of barotrauma. Jet ventilation must be used with extreme caution in patients with AAO due to the complex interplay between the various components of jet ventilation that affect the resultant minute volume and airway pressure. These components consist of: route (supraglottic, transglottic and translaryngeal/tracheal), ventilator parameters (driving pressure, frequency and inspiratory time), ventilator modalities (low, high or superimposed high frequency) and the effects of the stenosis itself. The degree of stenosis affects the degree of gas trapping, gas exhaust and entrainment. ${ }^{(87-89)}$ NAP4 reported a $65 \%$ failure rate with emergency needle cricothyroidotomy, but this is likely to be an overestimate as successful attempts would not have been reported. ${ }^{(3)}$

NAP4 emphasised that awake tracheostomy may offer a safer alternative to tracheal intubation after induction of anaesthesia, and that it should actively be considered. ${ }^{(3)}$ In addition, there were $\mathrm{CICV}$ cases that lent themselves well to AFOI or awake tracheostomy. Indications for awake tracheostomy for AAO of the upper airway include: severe stridor, large tumour, fixed hemilarynx, gross anatomical distortion and larynx not visible on flexible nasendoscopy. ${ }^{(2)}$ Emergency awake tracheostomy is lifesaving, but associated with a $7.8 \%-8.2 \%$ complication rate. ${ }^{(16,90)}$ NAP4 reported 29 successful first-choice emergency tracheostomies, ${ }^{(3)}$ with 11 being performed for true emergencies (i.e. patients in extremis). There were 2 (7\%) deaths. One was due to the tracheostomy not being able to bypass a low-lying lesion and the other was from pre-procedure severe hypoxia. Other studies found a $0 \%-2 \%$ incidence of death following emergency tracheostomy. ${ }^{(16,90}$

\section{Direct or indirect laryngoscopy}

Sir Robert Reynolds Macintosh introduced his laryngoscope blade in 1943 to elevate the epiglottis to facilitate intubation. ${ }^{(91)}$ It has been the mainstay for anaesthesiologists ever since, with direct laryngoscopy relying on the alignment of the oral, pharyngeal and laryngeal axes to view the glottis. ${ }^{(92)}$ The quest for newer techniques and technologies to overcome difficult laryngoscopy led to the development of indirect laryngoscopy, allowing the anaesthesiologist to 'look around the corner' to view the glottis. The prototype of the intubating fibreoptic bronchoscope (FOB) was described in $1967,{ }^{(93)}$ but only in 2001 was the first of a new generation of videolaryngoscopes (GlideScope $($; Verathon Company, Bothell, WA, USA) introduced. The 2003 ASA difficult airway algorithm was then updated a decade later with the addition of a fourth basic management choice of whether to use direct laryngoscopy or indirect laryngoscopy. ${ }^{(4,94)}$

There are three types of indirect laryngoscopy devices: nonguided blades (similar to the Macintosh laryngoscope); guided blades; and optical stylets. The latter are either flexible, e.g. FOB, or rigid, e.g. Bonfils fibrescope (Rusch Inc, Duluth, GA, USA). ${ }^{(95,96)}$ They allow the anaesthesiologist to 'look around the corner' by employing the use of fibreoptics, lenses, prisms, mirrors or a micro-camera. Theoretical advantages of indirect laryngoscopy over direct laryngoscopy are improved glottic views and increased chances of successful tracheal intubation, either as a primary or rescue technique after initial failure with direct laryngoscopy.

If asleep intubation is deemed safe, there are three functional characteristics that need to be considered before choosing the indirect laryngoscopy device in AAO cases: 
(a) Provision of an indirect view. All three types of devices are able to 'look around the corner' to view the glottis. Although nonguided blades may succeed in obtaining a full view of the glottis, correct placement of a tracheal tube may be difficult or impossible, even with the help of intubating aids such as stylets or bougies. $35 \%$ of failures to intubate with the GlideScope were associated with a Cormack-Lehane Grade 1 or 2 view. ${ }^{(97)}$

(b) Ability to guide a tracheal tube to the indirectly viewed glottis. Both guided blades and optic stylets have this ability. The former has an inbuilt 'conduit', whilst the latter allows railroading of a preloaded tracheal tube along its slender shaft.

(c) Ability to manoeuvre around an obstructing supraglottic lesion. Nonguided and guided blades are too bulky to allow much movement once inserted into the oral cavity; however, the thin and slender stylets can be manipulated in various directions to reveal a potential pathway to the glottis.

Two recent review articles summarised the performance of indirect laryngoscopy devices. One concluded that, in predicted or known difficult airways, the best-performing devices were the Bonfils, CTrach ${ }^{\text {TM }}$ and GlideScope. ${ }^{(96)}$ The other review recommended the Airtraq ${ }^{\circledR}, C$ Trach, GlideScope, Pentax AWS $®$ and Video Macintosh for patients with predicted difficult airways. ${ }^{(98)}$ The latter review recommended the Airtraq, Bonfils, Bullard $^{\mathrm{TM}}$, CTrach, GlideScope and Pentax AWS for known difficult intubation (Cormack-Lehane Grades 3 and 4). Results are difficult to interpret due to the lack of homogenous data. Unsurprisingly, there are no comparative studies investigating indirect laryngoscopy in patients with AAO due to the ethical issues involved. One study assessing GlideScope performance revealed that failure was most strongly associated with factors found in AAO: altered neck anatomy with a surgical scar, radiation changes and mass. ${ }^{(97)}$

Intubation using nonguided and guided blades involves inserting the device into the oral cavity, then steering a hollow tracheal tube towards and through the glottis, keeping the latter patent. Intubation using a flexible optical stylet requires a different sequence of events. The FOB needs to be inserted into the oral cavity (directly or via the nose) and then towards and through the glottis, and into the trachea. At this point, it can obstruct the airway. The preloaded tracheal tube is then railroaded over the $\mathrm{FOB}$ and passed into the trachea. Flexible AFOI is suitable for bypassing oropharyngeal lesions in elective cases, specifically base-of-tongue lesions, as these are associated with CICV (e.g. large tumours and lingual tonsillar hypertrophy). ${ }^{(3)}$ It is less suited for supraglottic or tracheal stenotic lesions, as the shaft of the FOB itself may exacerbate the pre-existing obstruction. Rigid stylets have the advantage of allowing one-handed operation, while the other hand can optimise the oropharyngeal airspace (e.g. using the thumb or laryngoscope). They can also be used to gently push an obstructive lesion out of the way.

In mild cases of obstruction, AFOI has been used successfully. ${ }^{(99-101)}$ However, in severe AAO, AFOl should be avoided, due to a number of factors. AFOI requires a calm, cooperative patient, which is unlikely in severe AAO. Airway topicalisation or intravenous sedation may cause loss of airway muscle tone or laryngospasm. ${ }^{(23-26)}$ Navigating the FOB may be technically challenging or impossible. If a friable tumour is the cause of the AAO, there is the risk of bleeding and a resultant acute loss of airway if contact is made with the FOB. Crucially, the passage of the FOB through a tight obstruction may be difficult or impossible, and risks causing a 'cork-in-a-bottle' scenario. ${ }^{(27,28)}$ Lastly, railroading the tracheal tube may also prove difficult or impossible in severe AAO.

\section{FORMULATING PLANS A, B AND C}

After a failed initial attempt at tracheal intubation in an anaesthetised patient, the overriding priority is ventilation and oxygenation of that patient. However, international difficult airway algorithms differ greatly in their Plans A, B and C, and each has its limitations in managing AAO. ${ }^{(102)}$ The UK Difficult Airway Society algorithm is based on low-strength evidence (expert committee reports or opinions, or clinical experience of respected authorities) with Strength D recommendations. ${ }^{(5,103)}$ Similarly, the ASA algorithm consists of predominantly Category B evidence (observational studies or randomised controlled trials without pertinent comparison groups). ${ }^{(4)}$ When Cook et $\mathrm{al}^{(30)}$ invited nine international airway experts to give their opinion on the management of AAO due to a retrosternal goitre, there was little consensus on Plan A. However, their Plan Bs almost unanimously recommended a rigid bronchoscope to help secure the airway.

Regardless of which difficult airway algorithm is adopted, NAP4 highlighted several requisites for the safe management of $\mathrm{AAO}:{ }^{(3)}$ (a) the need for skill and cooperation between the anaesthesiologist and airway surgeon; (b) a fully equipped environment with full surgical, anaesthetic and nursing support; (c) an operating theatre as the ideal location; (d) active consideration of awake tracheostomy as a safer alternative in appropriate cases; and (e) an instantly available surgical airway procedure, if it is part of a backup plan.

Once Plans A, B and C have been formulated, it is important to avoid fixation errors that may result in a failure to recognise and abort a plan that is not working, and be able to move to another potential solution. ${ }^{(3)}$ One high-fidelity simulation study showed that there were persistent deviations from the ASA difficult airway guidelines in the management of $\mathrm{CICV}$, particularly in the need to progress to a surgical airway procedure. ${ }^{(104)}$ They consisted of repeated intubation attempts, use of an FOB, bypassing the use of a laryngeal mask airway and failure to call for help early. These deviations occurred despite participants' involvement in an initial CICV scenario, followed by an intense one-hour debriefing session focusing on the correct guidelines and with cricothyroidotomy teaching.

Our template for Plans A, B and C (Fig. 1), based on the editorial by Mason et $\mathrm{al}_{,}{ }^{(2)}$ aim to lend structure to the decisionmaking processes of AAO: location, cause and degree of the obstruction, and consideration of the four basic management choices. ${ }^{(4,5)}$ The final goal is to encourage good clinical judgement on an individual or multidisciplinary basis. Some of the techniques 


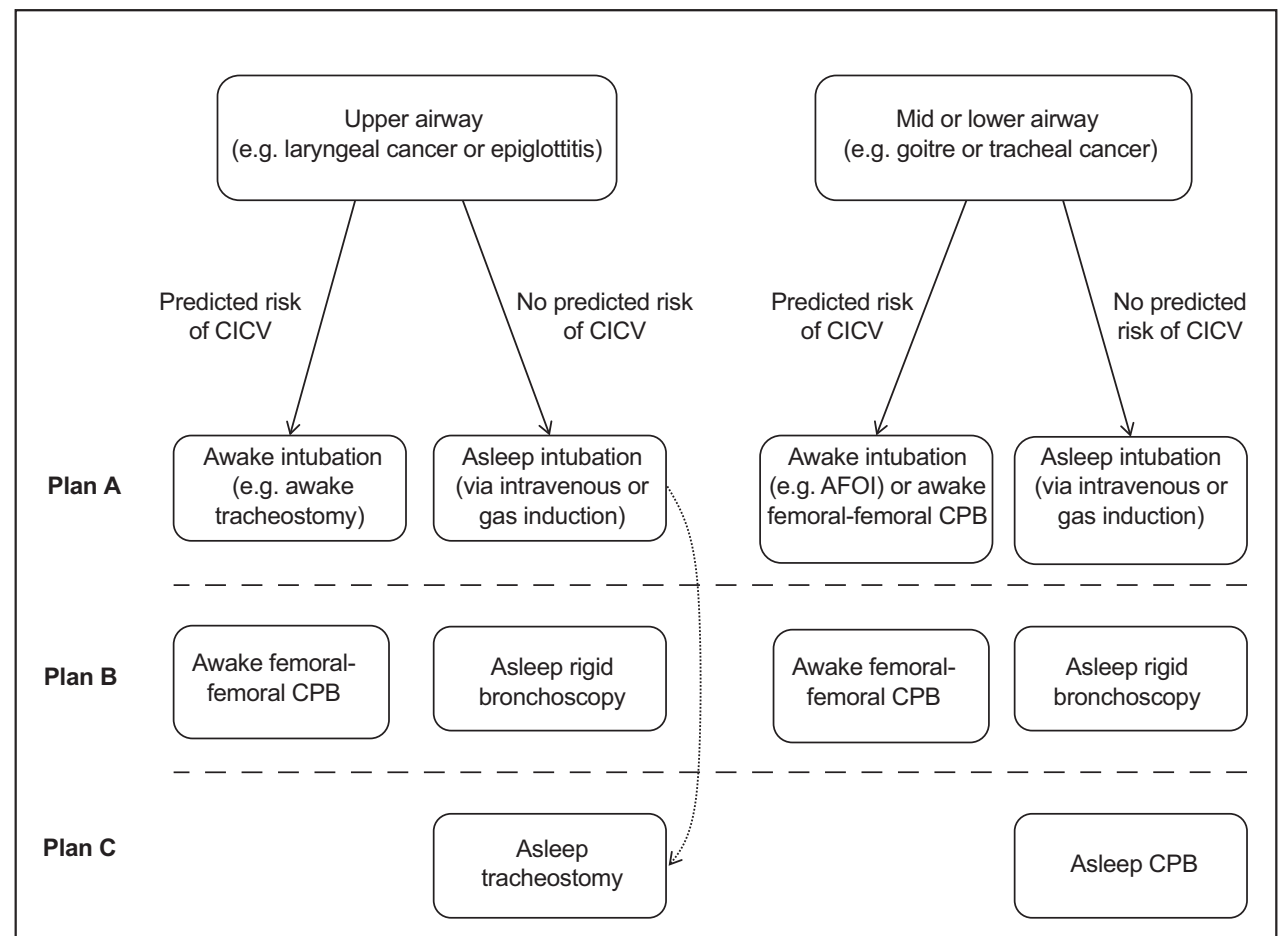

Fig. 1 Chart shows airway management strategy for acute airway obstruction using a template for Plans A, B and C. Movement may take place from Plan A to Plan C depending on patient and operator factors (broken arrow). AFOI: awake fibreoptic intubation; CICV: cannot intubate, cannot ventilate; CPB: cardiopulmonary bypass

or pathologies mentioned are beyond the scope of this article and references to more detailed management strategies are provided. For patients with $\mathrm{AAO}$ in the upper airway (e.g. a laryngeal tumour or acute epiglottitis):

1. No predicted risk of $\mathrm{CICV}$

(a) Plan A: asleep intubation (intravenous or gas induction). After induction, direct or indirect laryngoscopy is performed by the anaesthesiologist, and tracheal intubation attempted.

(b) Plan B: rigid bronchoscopy. ${ }^{(105)}$ This is performed by the airway surgeon and helps secure the airway. It allows implementation of conventional or jet ventilation, tamponades airway lesions and allows surgical procedures, both diagnostic and therapeutic, to be performed. It also helps promote a controlled environment, as the airway is secured and ventilation is taking place prior to Plan C, if the latter is necessary.

(c) Plan C: asleep tracheostomy. Occasionally, rigid bronchoscopy as Plan B is omitted and an emergency asleep tracheostomy is performed due to clinical necessity.

2. At risk of $\mathrm{CICV}$

(a) Plan A: awake intubation. Awake tracheostomy is most commonly performed, ${ }^{(16,90)}$ as AFOI is often contraindicated (see section 'Direct or indirect laryngoscopy').

(b) Plan B: cardiopulmonary bypass.

For patients with AAO in the mid-trachea and lower airway (e.g. large retrosternal goitre and tracheal tumour):

1. No predicted risk of $\mathrm{CICV}$

(a) Plan A: asleep intubation (intravenous or gas induction). Some authors strongly recommend preservation of SV as the negative intrathoracic pressure will help relieve any intrathoracic obstruction. This is achieved by gas induction and avoidance of muscle relaxants. ${ }^{(15,52)}$

(b) Plan B: rigid bronchoscopy.

(c) Plan C: cardiopulmonary bypass.

2. At risk of $\mathrm{CICV}$ :

(a) Plan A: awake intubation. This is most commonly AFOI, but there are dangers of a 'cork-in-a-bottle' scenario or laryngospasm. ${ }^{(23-28)}$ Awake tracheostomy is very difficult ${ }^{(33,34)}$ or impossible due to the underlying pathology (e.g. large retrosternal goitre) or being unable to bypass a low-lying central airway obstructive lesion.

(b) Plan B: cardiopulmonary bypass.

In rare cases of $\mathrm{AAO}$ in which it is not possible to access and bypass the lesion, failure to secure the airway may lead to a CICV scenario. Methods of maintaining oxygenation of the patient then rely on techniques that bypass the need for lung ventilation (e.g. cardiopulmonary bypass or extracorporeal membrane oxygenation). These blood oxygenators are connected to the patient via awake femoral vessel cannulation. Some researchers strongly recommend establishing cardiopulmonary bypass by cannulation under local anaesthesia and before induction of general anaesthesia. ${ }^{(15,52)}$ This is due to the risk of sudden cardiorespiratory collapse and the time needed for the bypass machine to be fully functional. Due to the logistical difficulties in setting up cardiopulmonary bypass, some authors have only established it after securing the airway, ${ }^{(81,82)}$ rather than before. ${ }^{(106-109)}$ Several cases of its successful use in central airway obstruction (including mediastinal mass syndrome) or symptomatic patients with large retrosternal goitres have been reported. ${ }^{(15,81,82,106-109)}$ 


\section{CONCLUSION}

The NAP4 report highlighted the poor management of AAO and subsequent complications in these patients. ${ }^{(3)}$ ASA's basic management choices and the algorithm by Mason et al provide the anaesthesiologist with a suitable template for formulating a logical primary and backup airway strategy. ${ }^{(2,4)}$ In addition, recent advances (such as the use of muscle relaxants and sugammadex, videolaryngoscopy, jet ventilation, and cardiopulmonary bypass) offer more options for anaesthesiologists. The decision-making process in AAO management should be based on individual circumstances, including patient status, location and extent of the obstruction, pathology, degree of urgency, and availability of expertise and facilities.

\section{REFERENCES}

1. Gray AJ, Hoile RW, Ingram GS, Sherry KM. The Report of the National Confidential Enquiry into Perioperative Deaths 1996/1997. London: NCEPOD, 1998.

2. Mason RA, Fielder CP. The obstructed airway in head and neck surgery. Anaesthesia 1999; 54:625-8.

3. Royal College of Anaesthetists. $4^{\text {th }}$ National Audit Project: Major Complications of Airway Management in the UK. London: Royal College of Anaesthetists, 2011.

4. Apfelbaum JL, Hagberg CA, Caplan RA, et al; American Society of Anesthesiologists Task Force on Management of the Difficult Airway. Practice guidelines for management of the difficult airway: an updated report by the American Society of Anesthesiologists Task Force on Management of the Difficult Airway. Anesthesiology 2013; 118:251-70.

5. Henderson JJ, Popat MT, Latto IP, Pearce AC; Difficult Airway Society. Difficult Airway Society guidelines for management of the unanticipated difficult intubation. Anaesthesia 2004; 59:675-94.

6. Calder I, Yentis SM. Could 'safe practice' be compromising safe practice? Should anaesthetists have to demonstrate that face mask ventilation is possible before giving a neuromuscular blocker? Anaesthesia 2008; 63:113-5.

7. Nouraei SA, Giussani DA, Howard DJ, et al. Physiological comparison of spontaneous and positive-pressure ventilation in laryngotracheal stenosis. $\mathrm{Br}$ J Anaesth 2008; 101:419-23.

8. Mendonca C. Sugammadex to rescue a 'can't ventilate' scenario in an anticipated difficult intubation: is it the answer? Anaesthesia 2013; 68:795-9.

9. Kurien M, Mathew J, Job A, Zachariah N. Ludwig's angina. Clin Otolaryngol Allied Sci 1997; 22:263-5.

10. Brook I. Microbiology and management of peritonsillar, retropharyngeal, and parapharyngeal abscesses. J Oral Maxillofac Surg 2004; 62:1545-50.

11. Hébert PC, Ducic Y, Boisvert D, Lamothe A. Adult epiglottitis in a Canadian setting. Laryngoscope 1998; 108(1 Pt 1):64-9.

12. Wong $\mathrm{P}$, Liew $\mathrm{GH}$, Kothandan $\mathrm{H}$. Anaesthesia for goitre surgery: A review. Proceedings Singapore Healthcare 2015; 24:165-70.

13. Ovassapian A, Glassenberg R, Randel GI, et al. The unexpected difficult airway and lingual tonsil hyperplasia: a case series and a review of the literature. Anesthesiology 2002; 97:124-32.

14. Ernst A, Feller-Kopman D, Becker HD, Mehta AC. Central airway obstruction. Am J Respir Crit Care Med 2004; 169:1278-97.

15. Erdös G, Tzanova I. Perioperative anaesthetic management of mediastinal mass in adults. Eur J Anaesthesiol 2009; 26:627-32.

16. Altman KW, Waltonen JD, Kern RC. Urgent surgical airway intervention: a 3 year county hospital experience. Laryngoscope 2005; 115:2101-4.

17. Olsson GL, Hallen B. Laryngospasm during anaesthesia. A computeraided incidence study in 136,929 patients. Acta Anaesthesiol Scand 1984; 28:567-75.

18. El-Orbany M, Woehlck HJ. Difficult mask ventilation. Anesth Analg 2009; 109:1870-80.

19. Mallampati SR, Gatt SP, Gugino LD, et al. A clinical sign to predict difficult tracheal intubation: a prospective study. Can Anaesth Soc J 1985; 32:429-34.

20. Shiga T, Wajima Z, Inoue T, Sakamoto A. Predicting difficult intubation in apparently normal patients: a meta-analysis of bedside screening test performance. Anesthesiology 2005; 103:429-37.

21. Kheterpal S, Healy D, Aziz MF, et al; Multicenter Perioperative Outcomes Group (MPOG) Perioperative Clinical Research Committee. Incidence, predictors, and outcome of difficult mask ventilation combined with difficult laryngoscopy: a report from the multicenter perioperative outcomes group. Anesthesiology 2013; 119:1360-9.

22. Jones $\mathrm{DH}$, Cohle SD. Unanticipated difficult airway secondary to lingual tonsillar hyperplasia. Anesth Analg 1993; 77:1285-8.

23. Shaw IC, Welchew EA, Harrison BJ, Michael S. Complete airway obstruction during awake fibreoptic intubation. Anaesthesia 1997; 52:582-5.

24. McGuire $\mathrm{G}$, el-Beheiry H. Complete upper airway obstruction during awake fibreoptic intubation in patients with unstable cervical spine fractures. Can J Anaesth 1999; 46:176-8.

25. Ho AM, Chung DC, Karmakar MK, et al. Dynamic airflow limitation after topical anaesthesia of the upper airway. Anaesth Intensive Care 2006; 34:211-5.

26. Bonner S, Taylor M. Airway obstruction in head and neck surgery. Anaesthesia 2000; 55:290-1.

27. Gilfillan N, Ball CM, Myles PS, et al. A cohort and database study of airway management in patients undergoing thyroidectomy for retrosternal goitre. Anaesth Intensive Care 2014; 42:700-8.

28. Huitink JM, Zijp L. Laryngeal radiation fibrosis: a case of failed awake flexible fibreoptic intubation. Case Rep Anesthesiol 2011; 2011:878910.

29. Dempsey GA, Snell JA, Coathup R, Jones TM. Anaesthesia for massive retrosternal thyroidectomy in a tertiary referral centre. Br J Anaesth 2013; 111:594-9.

30. Cook TM, Morgan PJ, Hersch PE. Equal and opposite expert opinion. Airway obstruction caused by a retrosternal thyroid mass: management and prospective international expert opinion. Anaesthesia 2011; 66:828-36.

31. Pemberton HS. Sign of submerged goitre. Lancet 1946; 248:509.

32. Voyagis GS, Kyriakos KP. The effect of goiter on endotracheal intubation. Anesth Analg 1997; 84:611-2.

33. Abraham D, Singh N, Lang B, Chan WF, Lo CY. Benign nodular goitre presenting as acute airway obstruction. ANZ J Surg 2007; 77:364-7.

34. El-Dawlatly AA, Takrouri MS, Elbakry A, et al. Perioperative management of huge goiter with compromized airway. Internet J Anesthesiol 2002; 7.

35. Han R, Tremper KK, Kheterpal S, O'Reilly M. Grading scale for mask ventilation. Anesthesiology 2004; 101:267.

36. Kheterpal S, Han R, Tremper KK, et al. Incidence and predictors of difficult and impossible mask ventilation. Anesthesiology 2006; 105:885-91.

37. Cormack RS, Lehane J. Difficult tracheal intubation in obstetrics. Anaesthesia 1984; 39:1105-11.

38. Rose DK, Cohen MM. The incidence of airway problems depends on the definition used. Can J Anaesth 1996; 43:30-4.

39. Hillman DR, Platt PR, Eastwood PR. The upper airway during anaesthesia. $\mathrm{Br}$ J Anaesth 2003; 91:31-9.

40. Hedenstierna G. Alveolar collapse and closure of airways: regular effects of anaesthesia. Clin Physiol Funct Imaging 2003; 23:123-9.

41. Tokics L, Hedenstierna G, Strandberg A, Brismar B, Lundquist H. Lung collapse and gas exchange during general anesthesia: effects of spontaneous breathing, muscle paralysis, and positive end-expiratory pressure. Anesthesiology 1987; 66:157-67.

42. Rothen HU, Sporre B, Engberg G, Wegenius G, Hedenstierna G. Airway closure, atelectasis and gas exchange during general anaesthesia. $\mathrm{Br}$ J Anaesth 1998; 81:681-6.

43. Baraka AS, Taha SK, Aouad MT, El-Khatib MF, Kawkabani NI. Preoxygenation: comparison of maximal breathing and tidal volume breathing techniques. Anesthesiology 1999; 91:612-6.

44. Patel A, Nouraei SA. Transnasal Humidified Rapid-Insufflation Ventilatory Exchange (THRIVE): a physiological method of increasing apnoea time in patients with difficult airways. Anaesthesia 2015; 70:323-9.

45. Cook TM. A new practical classification of laryngeal view. Anaesthesia 2000; 55:274-9.

46. Arné J, Descoins P, Fusciardi J, et al. Preoperative assessment for difficult intubation in general and ENT surgery: predictive value of a clinical multivariate risk index. Br J Anaesth 1998; 80:140-6.

47. Canning BJ. Reflex regulation of airway smooth muscle tone. J Appl Physiol 2006; 101:971-85.

48. Nagaro T, Yorozuya T, Sotani M, et al. Survey of patients whose lungs could not be ventilated and whose trachea could not be intubated in university hospitals in Japan. J Anesth 2003; 17:232-40.

49. Wood A, Choromanski D, Orlewicz M. Intubation of patients with angioedema: A retrospective study of different methods over three year period. Int J Crit IIIn Inj Sci 2013; 3:108-12.

50. McGuire BE. Use of the McGrath video laryngoscope in awake patients. Anaesthesia 2009; 64:912-4.

51. Ramaswamy AH, Kurdi MS, Shaikh SI, Deva RS, Raza SU. Awake rigid bronchoscopy for post intubation tracheal stenosis. Anaesth Pain Intensive Care 2014; 18:299-301

52. Slinger $P$, Karsli C. Management of the patient with a large anterior mediastinal mass: recurring myths. Curr Opin Anaesth 2007; 20:1-3.

53. Kimura T, Watanabe $\mathrm{S}$, Asakura $\mathrm{N}$, et al. Determination of end-tidal sevoflurane concentration for tracheal intubation and minimum alveolar anesthetic concentration in adults. Anesth Analg 1994; 79:378-81.

54. Scheller MS, Saidman LJ, Partridge BL. MAC of sevoflurane in humans and the New Zealand white rabbit. Can J Anaesth 1988; 35:153-6. 
55. Katoh T, Ikeda K. The minimum alveolar concentration (MAC) of sevoflurane in humans. Anesthesiology 1987; 66:301-3.

56. Muzi M, Robinson BJ, Ebert TJ, O'Brien TJ. Induction of anesthesia and tracheal intubation with sevoflurane in adults. Anesthesiology 1996; 85:536-43.

57. Lowry DW, Carroll MT, Mirakhur RK, et al. Comparison of sevoflurane and propofol with rocuronium for modified rapid-sequence induction of anaesthesia. Anaesthesia 1999; 54:247-52.

58. Watson KR, Shah MV. Clinical comparison of 'single agent' anaesthesia with sevoflurane versus target controlled infusion of propofol. Br J Anaesth 2000; 85:541-6.

59. Dashfield AK, Birt DJ, Thurlow J, Kestin IG, Langton JA. Recovery characteristics using single-breath $8 \%$ sevoflurane or propofol for induction of anaesthesia in day-case arthroscopy patients. Anaesthesia 1998; 53:1062-6.

60. Benumof JL, Dagg R, Benumof R. Critical hemoglobin desaturation will occur before return to an unparalyzed state following $1 \mathrm{mg} / \mathrm{kg}$ intravenous succinylcholine. Anesthesiology 1997; 87:979-82.

61. Talbot NP, Farmery AD, Dorrington KL. End-tidal sevoflurane and halothane concentrations during simulated airway occlusion in healthy humans. Anesthesiology 2009; 111:287-92.

62. Girgis Y, Frerk CM, Pigott D. Redistribution of halothane and sevoflurane under simulated conditions of acute airway obstruction. Anaesthesia 2001; 56:613-5.

63. Baillard C, Adnet F, Borron SW, et al. Tracheal intubation in routine practice with and without muscular relaxation: an observational study. Eur Anaesthesiol 2005; 22:672-7.

64. Lieutaud T, Billard V, Khalaf H, Debaene B. Muscle relaxation and increasing doses of propofol improve intubating conditions. Can J Anaesth 2003; 50:121-6.

65. Mencke T, Echternach $M$, Kleinschmidt S, et al. Laryngeal morbidity and quality of tracheal intubation: a randomized controlled trial. Anesthesiology 2003; 98:1049-56.

66. Warters RD, Szabo TA, Spinale FG, DeSantis SM, Reves JG. The effect of neuromuscular blockade on mask ventilation. Anaesthesia 2011; 66:163-7.

67. Cooper R, Mirakhur RK, Clarke RS, Boules Z. Comparison of intubating conditions after administration of Org 9246 (rocuronium) and suxamethonium. Br J Anaesth 1992; 69:269-73.

68. Dubois PE, Mulier JP. A review of the interest of sugammadex for deep neuromuscular blockade management in Belgium. Acta Anaesthesiol Belg 2013; 64:49-60.

69. Sørensen MK, Bretlau C, Gätke MR, Sørensen AM, Rasmussen LS. Rapid sequence induction and intubation with rocuronium-sugammadex compared with succinylcholine: a randomized trial. Br J Anaesth 2012; 108:682-9.

70. Curtis R, Lomax S, Patel B. Use of sugammadex in a 'can't intubate, can't ventilate' situation. Br J Anaesth 2012; 108:612-4.

71. Paton L, Gupta S, Blacoe D. Successful use of sugammadex in a 'can't ventilate' scenario. Anaesthesia 2013; 68:861-4.

72. Watson SJ, Jefferson P, Ball DR. Sugammadex and the cannot intubate/cannot ventilate scenario in patients with predicted difficult airway (1). Letter $3 . \mathrm{Br}$ J Anaesth 2012; 109:460-1; author reply 461-2.

73. Telgarsky B, Stacey M. Sugammadex and the cannot intubate/cannot ventilate scenario in patients with predicted difficult airway (1). Letter 2. Br J Anaesth 2012; 109:459-60; author reply 461-2.

74. Ezri T, Evron S. Sugammadex and the cannot intubate/cannot ventilate scenario in patients with predicted difficult airway (1). Letter 1. Br J Anaesth 2012; 109:459; author reply 461-2.

75. Turnbull J, Suaris P. Sugammadex in anticipated difficult airways(1.). Anaesthesia 2013; 68:1189-90.

76. Elliott SK, Ball DR. Sugammadex in anticipated difficult airways(2.) Anaesthesia 2013; 68:1190.

77. Dalton AJ, McGuire B, Rodney G. Sugammadex in anticipated difficult airways(4.). Anaesthesia 2013; 68:1191-2.

78. Copp MV. Sugammadex in anticipated difficult airways(5.). Anaesthesia 2013; 68:1192.

79. Benham SW. Sugammadex in anticipated difficult airways(3.). Anaesthesia 2013; 68:1190-1.

80. Bisschops MM, Holleman C, Huitink JM. Can sugammadex save a patient in a simulated 'cannot intubate, cannot ventilate' situation? Anaesthesia 2010; 65:936-41.

81. Reid AW, Warmington AD, Wilkinson LM. Management of a pregnant patien with airway obstruction secondary to goitre. Anaesth Intensive Care 1999; 27:415-7.

82. Tan PC, Esa N. Anesthesia for massive retrosternal goiter with severe intrathoracic tracheal narrowing: the challenges imposed -A case report-. Korean J Anesthesiol 2012; 62:474-8.

83. Vorasubin N, Vira D, Jamal N, Chhetri DK. Airway management and endoscopic treatment of subglottic and tracheal stenosis: the laryngeal mask airway technique. Ann Otol Rhinol Laryngol 2014; 123:293-8

84. Cook TM, Asif M, Sim R, Waldron J. Use of a ProSeal laryngeal mask airway and a Ravussin cricothyroidotomy needle in the management of laryngeal and subglottic stenosis causing upper airway obstruction. Br J Anaesth 2005; 95:554-7.

85. Patel B, Frerk C. Large-bore cricothyroidotomy devices. Contin Educ Anaesth Crit Care Pain 2008; 8:157-60

86. Ross-Anderson DJ, Ferguson C, Patel A. Transtracheal jet ventilation in 50 patients with severe airway compromise and stridor. Br J Anaesth 2011; 106:140-4

87. Ng A, Russell WC, Harvey N, Thompson JP. Comparing methods of administering high-frequency jet ventilation in a model of laryngotracheal stenosis. Anesth Analg 2002; 95:764-9.

88. Leiter R, Aliverti A, Priori R, et al. Comparison of superimposed high-frequency jet ventilation with conventional jet ventilation for laryngeal surgery. $\mathrm{Br}$ J Anaesth 2012; 108:690-7.

89. Buczkowski PW, Fombon FN, Lin ES, Russell WC, Thompson JP. Air entrainment during high-frequency jet ventilation in a model of upper tracheal stenosis. Br J Anaesth 2007; 99:891-7.

90. Yuen HW, Loy AH, Johari S. Urgent awake tracheotomy for impending airway obstruction. Otolaryngol Head Neck Surg 2007; 136:838-42.

91. Jephcott A. The Macintosh laryngoscope. A historical note on its clinical and commercial development. Anaesthesia 1984; 39:474-9.

92. El-Orbany M, Woehlck H, Salem MR. Head and neck position for direct laryngoscopy. Anesth Analg 2011; 113:103-9.

93. Murphy P. A fibre-optic endoscope used for nasal intubation. Anaesthesia 1967; 22:489-91.

94. American Society of Anesthesiologists Task Force on Management of the Difficult Airway. Practice guidelines for management of the difficult airway: an updated report by the American Society of Anesthesiologists Task Force on Management of the Difficult Airway. Anesthesiology 2003; 95:1269-77.

95. McGuire BE, Younger RA. Rigid indirect laryngoscopy and optical stylets. Contin Educ Anaesth Crit Care Pain 2010; 10:148-51.

96. Mihai $\mathrm{R}$, Blair E, Kay H, Cook TM. A quantitative review and meta-analysis of performance of non-standard laryngoscopes and rigid fibreoptic intubation aids. Anaesthesia 2008; 63:745-60.

97. Aziz MF, Healy D, Kheterpal S, et al. Routine clinical practice effectiveness of the Glidescope in difficult airway management: an analysis of 2,004 Glidescope intubations, complications, and failures from two institutions. Anesthesiology 2011; 114:34-41.

98. Healy DW, Maties O, Hovord D, Kheterpal S. A systematic review of the role of videolaryngoscopy in successful orotracheal intubation. BMC Anesthesiol 2012; $12: 32$.

99. Huitink JM, Buitelaar DR, Schutte PF. Awake fibrecapnic intubation: a novel technique for intubation in head and neck cancer patients with a difficult airway. Anaesthesia 2006; 61:449-52.

100. Tantry TP, Hrishi AP, Koteshwar R, Shenoy SP, Adappa KK. Acute epiglottic abscess in adults: Still a challenge! J Anaesthesiol Clin Pharmacol 2011; 27:426-8.

101. Rashid J, Warltier B. Awake fibreoptic intubation for a rare cause of upper airway obstruction--an infected laryngocoele. Anaesthesia 1989; 44:834-6.

102. Frova G, Sorbello M. Algorithms for difficult airway management: a review. Minerva Anestesiol 2009; 75:201-9.

103. Shekelle PG, Woolf SH, Eccles M, Grimshaw J. Clinical guidelines: developing guidelines. BMJ 1999; 318:593-6.

104. Borges BC, Boet S, Siu LW, et al. Incomplete adherence to the ASA difficult airway algorithm is unchanged after a high-fidelity simulation session. Can J Anaesth 2010; 57:644-9.

105. Chao YK, Liu YH, Hsieh MJ, et al. Controlling difficult airway by rigid bronchoscope--an old but effective method. Interact Cardiovasc Thorac Surg 2005; 4:175-9

106. Radauceanu DS, Dunn JO, Lagattolla N, Farquhar-Thomson D. Temporary extracorporeal jugulosaphenous bypass for the peri-operative management of patients with superior vena caval obstruction: a report of three cases. Anaesthesia 2009; 64:1246-9.

107. Sendasgupta C, Sengupta G, Ghosh K, Munshi A, Goswami A. Femoro-femoral cardiopulmonary bypass for the resection of an anterior mediastinal mass. Indian J Anaesth 2010; 54:565-8.

108. Wang G, Lin S, Yang L, Wang Z, Sun Z. Surgical management of tracheal compression caused by mediastinal goiter: is extracorporeal circulation requisite? J Thorac Dis 2009; 1:48-50.

109. Berg EV, Gomes HJ, Conturie CL, Wein RO. Case report of multinodular goiter and airway compression in a preeclamptic patient. J Anesthesiol Clin Sci $2012 ; 1: 1-10$. 